\title{
Phytoplankton dynamics driven by vertical nutrient fluxes during the spring inter-monsoon period in the northeastern South China Sea
}

\author{
Q. P. Li, Y. Dong, and Y. Wang \\ State Key Lab of Tropical Oceanography, South China Sea Institute of Oceanology, Chinese Academy of Sciences, \\ Guangzhou, China
}

Correspondence to: Q. P. Li (qianli@ @scsio.ac.cn)

Received: 27 March 2015 - Published in Biogeosciences Discuss.: 5 May 2015

Revised: 2 December 2015 - Accepted: 24 December 2015 - Published: 22 January 2016

\begin{abstract}
A field survey from the coastal ocean zones to the offshore pelagic zones of the northeastern South China Sea (nSCS) was conducted during the inter-monsoon period of May 2014 when the region was characterized by prevailing low-nutrient conditions. Comprehensive field measurements were made for not only hydrographic and biogeochemical properties but also phytoplankton growth and microzooplankton grazing rates. We also performed estimations of the vertical turbulent diffusivity and diffusive nutrient fluxes using a Thorpe-scale method and the upwelling nutrient fluxes by Ekman pumping using satellite-derived wind stress curl. Our results indicated a positive correlation between the integrated phytoplankton chlorophyll $a$ and vertical nutrient fluxes in the offshore region of the nSCS during the study period. We generally found an increasing role of turbulent diffusion but a decreasing role of curl-driven upwelling in vertical transport of nutrients from the coastal ocean zones to the offshore pelagic zones. Elevated nutrient fluxes near Dongsha Islands supported high new production leading to net growth of the phytoplankton community, whereas the low fluxes near the southwest of Taiwan had resulted in a negative net community growth leading to decline of a surface phytoplankton bloom. Overall, phytoplankton dynamics in the large part of the nSCS could be largely driven by vertical nutrient fluxes including turbulent diffusion and curl-driven upwelling during the spring inter-monsoon period.
\end{abstract}

\section{Introduction}

Nutrient fluxes from below the euphotic zone are essential for phytoplankton primary production in the surface ocean (Eppley and Peterson, 1979), while the mechanisms regulating those fluxes are still inadequately understood in the northeastern South China Sea (nSCS), particularly during the spring inter-monsoon period. Wind-driven coastal upwelling, river discharge and inter-shelf nutrient transport were important mechanisms supplying nutrients to the euphotic zone of the nSCS (Liu et al., 2002; Gan et al., 2010; Han et al., 2013), while their contributions to primary production were mostly limited to coastal regions as these nutrients would be mostly utilized in the coastal waters before reaching the large area of the nSCS. Kuroshio intrusion would dilute the nSCS waters with the low-nutrient North Pacific waters (Farris and Wimbush, 1996), which appeared to be much weaker during April-September (Centurioni et al., 2004). Contribution of nitrogen fixation to new production of the nSCS was generally negligible compared to the nitrate-based new production (Chen, 2005; Bombar et al., 2010). Atmospheric deposition of anthropogenic nitrogen could support up to $\sim 20 \%$ of the annual new production in the nSCS exceeding those from riverine inputs (Kim et al., 2013). However, its contribution would be much less during the spring inter-monsoon season as the reduced rate of atmospheric deposition (Lin et al., 2009).

Diapycnal mixing by turbulent dissipation was recently found to be important for the supply of new nitrogen in the nSCS, where the vertical turbulent diffusivities were an order of magnitude higher than the adjacent West Pacific Ocean 
(Tian et al., 2009; Liu and Lozovatsky, 2012; Yang et al., 2014). It was also suggested that phytoplankton blooms off the west coast of the nSCS could be induced by wind stress curl-driven upwelling during the spring inter-monsoon season (Wang and Tang, 2014), which would cause a local uplift of isopycnals leading to nutrient injection into the euphotic zone with subsequent changes of community structure and productivity (Rykaczewski and Checkley, 2008; Li et al., 2015). By modifying the surface wind stress and wind stress curl via air-sea coupling, the eddy-induced Ekman pumping (Gaube et al., 2013) was important for phytoplankton production in the $\mathrm{nSCS}$ during the inter-monsoon transition period (Lin et al., 2010). As both intermittent turbulent diffusion and wind-driven Ekman pumping affect the vertical transport of nutrients on temporal scales similar to the generation time of phytoplankton, they will have large influences on plankton dynamics of the upper ocean (Cullen et al., 2002). It is therefore important to investigate the roles of these two mechanisms in driving the variability of phytoplankton biomass and primary production in the large area of the nSCS.

The spatial distribution of phytoplankton at sea is a result of complex interactions between physical and biological processes (Davis et al., 1991; Abraham, 1998). In addition to the vertical nutrient fluxes, phytoplankton biomass and productivity of the nSCS are influenced by growth-grazing dynamics (Chen, 2005; Huang et al., 2011; Zhou et al., 2011; Chen et al., 2013). Shifts in the dominance of phytoplankton species in the western South China Sea were believed to be driven by a close coupling of the mortality rates of different phytoplankton groups via common grazers such as nanoflagellates (Chen et al., 2009). There was on average $\sim 61 \%$ of phytoplankton growth lost to microzooplankton grazing in coastal upwelling regions of the nSCS in response to increased nutrient fluxes, whereas growth and grazing mortality rates were mostly balanced on the shelf and shelf break areas without upwelling events (Huang et al., 2011). It was also suggested that the balance of phytoplankton growth and microzooplankton grazing in the pelagic nSCS could be perturbed by physical disturbances such as eddies, fronts and typhoons, leading to large deviations of planktonic ecosystem from the steady state (Zhou et al., 2011; Chen et al., 2013).

Here, we present results of a field survey from the coastal ocean zones to the offshore pelagic zones in the nSCS conducted during the spring inter-monsoon transition of May 2014, when the region was characterized by prevailing low-nutrient conditions as a result of weak and variable winds (Lin et al., 2010). Comprehensive measurements were made for hydrographic and biogeochemical properties, as well as biological rates including phytoplankton growth and grazing rates and net nutrient consumption rates. We also performed estimations of the vertical turbulent diffusivity and diffusive nutrient fluxes using a Thorpe-scale method (Gargett and Garner, 2008; Li et al., 2012) and the upwelling nutrient fluxes by Ekman pumping using satellite-derived wind stress curl (Gill, 1982; Risien and Chelton, 2008). In synthesizing these field data, the focus of this paper is to (1) investigate the spatial patterns of vertical nutrient fluxes in the nSCS, (2) determine the relative roles of turbulent diffusion and Ekman pumping to vertical transport of nutrients in the upper ocean, and (3) understand the linkage between vertical nutrient fluxes and phytoplankton dynamics in the nSCS during the spring inter-monsoon period.

\section{Materials and methods}

\subsection{Site description, field sampling and measurements}

There are typically high nutrients in the coastal regions of the nSCS due to river discharge, inter-shelf transport, and upwelling and mixing (Gan et al., 2010), in contrast to the oligotrophic low-latitude offshore regions with strong stratification. The nSCS is also strongly influenced by Kuroshio intrusion through the Luzon Strait (Farris and Wimbush, 1996). The intruded Kuroshio waters with higher temperature and salinity but lower nutrients are often transported westward via eddies and Ekman advection (Centurioni et al., 2004) influencing the large area of the nSCS on seasonal timescales.

A field survey of the nSCS (Fig. 1) was conducted during May 2014 aboard the R/V Shiyan III of the South China Sea Institute of Oceanology. From 14 to 16 May 2014, a transect from the coastal waters near Shantou to the offshore waters near the Luzon Strait was comprehensively sampled to investigate the spatial patterns of hydrographic and biogeochemical properties of the nSCS. Station $\mathrm{S}_{1}\left(22^{\circ} \mathrm{N}, 119.5^{\circ} \mathrm{E}\right)$ was chosen as a reference time-series station with continuous CTD sampling of 13 casts within $24 \mathrm{~h}$ (start: 10:00 GMT+8, 18 May 2014). Station A ( $21.9^{\circ} \mathrm{N}, 120^{\circ} \mathrm{E}$ with a bottom depth of $1547 \mathrm{~m}$ ) near the southwest of Taiwan and station B $\left(20.5^{\circ} \mathrm{N}, 117^{\circ} \mathrm{E}\right.$ with a bottom depth of $\left.607 \mathrm{~m}\right)$ in the southeast of Dongsha Islands were selected for dilution experiments to quantify phytoplankton growth and microzooplankton grazing rates.

Discrete seawater samples at depths of $0,25,50,75,100$, 200, 300, 500, and $700 \mathrm{~m}$ were collected using a SeaBird SBE 9/11 CTD rosette water sampler system, providing high-resolution hydrographic measurements of the upper water column with internal pressure, conductivity and temperature sensors. We define the euphotic zone as the layer above $1 \%$ of surface photosynthetically active radiation (PAR), measured by a PAR sensor (QSP200L, Biospherical Instrument, Inc.). After inline filtration from the PVC Niskin bottles through $0.8 \mu \mathrm{m}$ Nuclepore filters, seawater samples for nutrients were frozen immediately and stored in a refrigerator until final analyses after the cruise. For chlorophyll $a$ sampling, $500 \mathrm{~mL}$ of seawater was gently filtered $(<50 \mathrm{~mm}$ $\mathrm{Hg}$ ) through a GF/F (Whatman) filter, which was wrapped in a piece of aluminum foil and kept at $-20^{\circ} \mathrm{C}$ on board. Upon return to the lab, chlorophyll $a$ samples were sonicated 


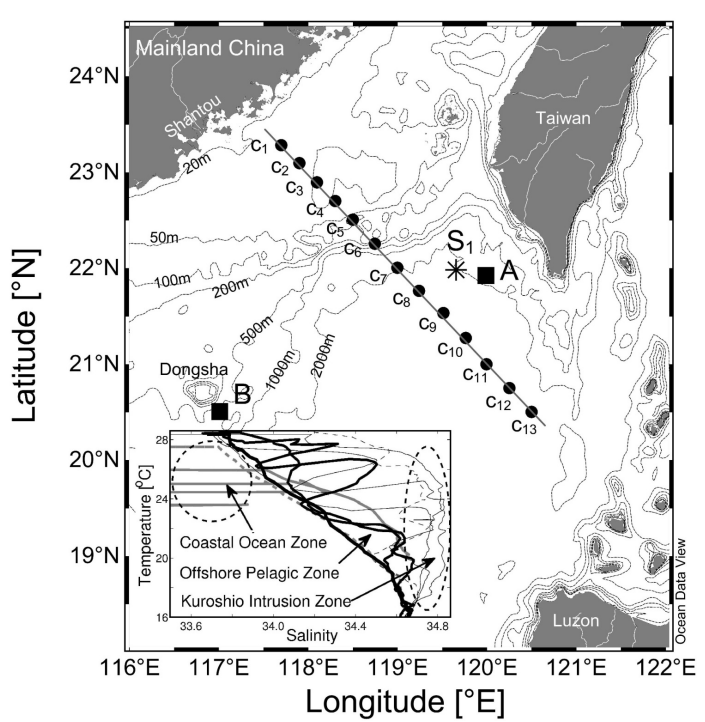

Figure 1. Sampling map in the northeastern South China Sea during May 2014. Dashed lines show the topography of the study area; solid dots are the stations for a transect study $\left(\mathrm{C}_{1-13}\right)$ during the period 14-16 May 2014; star is a time-series reference station $\left(\mathrm{S}_{1}\right)$; filled squares are two stations where shipboard dilution experiments were performed (A and B). Inset shows the temperature/salinity diagram for the transect with arrows indicating waters from the coastal ocean zone (thick gray lines), the offshore pelagic zone (thick black lines), and the Kuroshio intrusion zone (thin lines).

for $20 \mathrm{~min}$ and extracted in $5 \mathrm{~mL} 90 \%$ acetone at $4{ }^{\circ} \mathrm{C}$ in the dark for $24 \mathrm{~h}$. These samples were centrifuged at $4000 \mathrm{rpm}$ for $10 \mathrm{~min}$ before final determinations by standard fluorescence methods (Parsons et al., 1984) using a Turner Designs Model 10 Fluorometer. Concentrations of nitrate plus nitrite, phosphate and silicate were determined by a Seal AA3 auto analyzer (Bran-Luebbe, $\mathrm{GmbH}$ ). The low concentrations of nitrate plus nitrite and phosphate within the euphotic zone were also determined by the long-cell method ( $\mathrm{Li}$ et al., 2008; Li and Hansell, 2008) by incorporating a $50 \mathrm{~cm}$ liquid waveguide cell to AA3 with detection limits of $\sim 0.02$ and $\sim 0.01 \mu \mathrm{M}$, respectively.

\subsection{Remote sensing observations}

High-resolution satellite data, including sea surface temperature (SST), sea surface chlorophyll (SSChl), surface geostrophic velocities, as well as surface wind stresses and Ekman velocities, were used to assess the spatial change of these surface properties in the nSCS during the study period. Monthly averaged sea surface chlorophyll $a\left(0.04^{\circ} \times 0.04^{\circ}\right)$ was acquired from the NASA's Moderate Resolution Imaging Spectroradiometer data observed by the Aqua Satellite (MODIS-Aqua). Surface velocity fields $\left(0.3^{\circ} \times 0.3^{\circ}\right)$ were derived from multi-satellite altimeter (TOPEX, JASON-1, ERS-2, ENVISAT and GFO) and scatterometer data distributed by the NOAA's Ocean Sur- face Current Analysis-Realtime (OSCAR) program, which had been largely validated by a variety of field measurements including global drifts, moorings, and shipboard ADCP. Daily sea surface temperature $\left(0.1^{\circ} \times 0.1^{\circ}\right)$ was acquired from the NOAA's Geostationary Operational Environmental Satellite-Polar Operational Environmental Satellite program (GOES-POES). Daily Ekman upwelling velocities and surface wind stresses with a resolution of $0.25^{\circ} \times 0.25^{\circ}$ were derived from the Advanced Scatterometer data by the European Meteorological and Operational satellite program (METOPASCAT). The Ekman pumping velocity ( $w_{\mathrm{e}}$, negative for downwelling) at the depth of Ekman layer is calculated as (Gill, 1982)

$w_{\mathrm{e}}=\frac{1}{\rho_{\mathrm{w}}}\left(\nabla \times \frac{\tau}{f}\right)$,

where $\rho_{\mathrm{w}}$ is the density of seawater, which is assumed constant at $1024 \mathrm{~kg} \mathrm{~m}^{-3} ; f$ is the Coriolis parameter; $\tau$ is the vector of wind stress.

\subsection{Thorpe-scale analyses and vertical diffusivity}

We applied a Thorpe-scale based approach (Thorpe, 1977; Galbraith and Kelley, 1996; Gargett and Garner, 2008; Li et al., 2012) to estimate fine structure and turbulent diffusivity for each station using CTD downcast data. The method combines several criteria to determine the real overturns from a density profile ( $\mathrm{Li}$ et al., 2012), including the test of minimum thickness, the run-length and water mass tests (Galbraith and Kelley 1996), as well as the tests of minimal overturn ratio and maximal $T / S$ tightness (Gargett and Garner, 2008). These criteria ensure that the maximal density difference within an overturn is greater than twice the measurement noise $\left(0.001 \mathrm{~kg} \mathrm{~m}^{-3}\right)$. The length scale of an overturn is larger than twice the vertical resolution (Nyquist theorem) and larger than a minimum thickness (Galbraith and Kelley, 1996). The percentage of positive/negative displacements within an overturn (the overturn ratio) is larger than 0.2 and the deviations on a $T / S$ diagram are less than 0.003 (Gargett and Garner, 2008). The vertical resolution of CTD sampling during the cruise was $\sim 10 \mathrm{~cm}$ with a fall rate of $\sim 2.4 \mathrm{~m} \mathrm{~s}^{-1}$. Therefore, only overturns larger than $0.5 \mathrm{~m}$ are included, to obtain five data point resolution. We discard data in the upper $10 \mathrm{~m}$, as the Thorpe approach is not strictly valid there. Once an overturn is identified, the Thorpe scale $\left(L_{\mathrm{T}}\right)$ is calculated from the root mean square of the vertical displacement $\left(d_{z}\right)$ as $L_{\mathrm{T}}=\left(\Sigma d_{z}^{2}\right)^{0.5}$.

Turbulent kinetic energy dissipation rate $(\varepsilon)$ is calculated from $L_{\mathrm{T}}$ and $N$ by

$\varepsilon=0.64 \cdot L_{\mathrm{T}}^{2} \cdot N^{3}$,

where $N$ is the buoyancy frequency given by $N^{2}=$ $-g \rho_{0}^{-1}(\partial \rho / \partial z)$ with $g$ the gravitational acceleration, $\rho_{0}$ the mean density, and $\partial \rho / \partial z$ the density gradient across each 
overturn (Galbraith and Kelley, 1996). According to Osborn (1980), the vertical diffusivity $\left(K_{z}\right)$ can be estimated from $\varepsilon$ and $N$ by

$$
K_{z}=0.2 \cdot \varepsilon \cdot N^{-2} \text {. }
$$

The diffusive nutrient fluxes at the depth of interest can be estimated by multiplying the diffusivity $\left(K_{z}\right)$ by the local nutrient gradient $(\partial C / \partial z)$. Nutrient gradient, at the depth of $Z_{i}$ with the concentration of $C_{i}$, is approximately estimated by $\left(C_{i+1}-C_{i}\right) /\left(Z_{i+1}-Z_{i}\right)$, with $C_{i+1}$ the concentrations at $Z_{i+1}$ immediately next to $Z_{i}$.

\subsection{Setup of dilution experiments}

Phytoplankton growth and microzooplankton grazing in the surface waters of stations A and B near the edge of the continental shelf were assessed on board using dilution technique (Landry and Hassett, 1982; Landry et al., 1998; Li et al., 2011) on 13 and 17 May 2014. All the bottles, tubing and carboys were soaked in $10 \%(v / v)$ hydrochloric acid solution for over $24 \mathrm{~h}$ and they were rinsed several times with deionized water and seawater before each experiment. Surface seawater, collected by an acid-washed polyethylene bucket, was screened through a $200 \mu \mathrm{m}$ mesh before being transferred into polycarbonate carboys as raw seawater. A dilution series was prepared with $0,25,50,75$ and $100 \%$ unfiltered seawater in duplicated polycarbonate bottles $(0 \%$ unfiltered seawater sample was not performed at station B). Measured amounts of particle-free seawater, obtained by filtering the raw seawater with $0.45 \mu \mathrm{m}$ filters, were added to 2.4-L polycarbonate bottles. These samples were then enriched with additional nutrients to promote constant growth of phytoplankton. Finally, each bottle was gently filled with unfiltered seawater to its capacity. There was also one bottle filled with $100 \%$ unfiltered raw seawater without nutrient enrichment to serve as the control for our experiment. All the bottles were tightly capped and incubated for $24 \mathrm{~h}$ in a deck incubator, which was covered with a neutral density screen to mimic the natural sunlight and filled with flowing seawater from the sea surface to control the temperature. Duplicate $300 \mathrm{~mL}$ samples were taken from each bottle before and after the dilution experiments for chlorophyll $a$ measurements.

Specific rates of nutrient-saturated phytoplankton growth $\left(\mu_{\mathrm{n}}, \mathrm{d}^{-1}\right)$ and microzooplankton grazing $\left(g, \mathrm{~d}^{-1}\right)$ are estimated by least-square regression between the net growth rates $\left(\eta, \mathrm{d}^{-1}\right)$ and the dilution factors $(D)$ as

$\eta=\frac{1}{t} \ln \left(\frac{P_{t}}{P_{0}}\right)=\mu_{\mathrm{n}}-D \cdot g$,

where $P_{0}$ and $P_{t}$ are the initial and final concentrations of chlorophyll $a$, respectively and $t$ is the duration of the incubation. The natural phytoplankton growth rate $(\mu)$, which is often subjected to nutrient limitation (Landry et al., 1998), is finally estimated from the net growth rate of raw seawater without nutrient enrichment $\left(\eta_{\text {raw }}\right)$ by $\mu=\eta_{\text {raw }}+g$.
To examine the response of the phytoplankton community to nutrient enrichment, two bottles of raw seawater with nutrient additions were incubated for 4 days, with chlorophyll $a$ and nutrient samples taken at the very beginning and each day afterwards. Nutrient data within the exponential growth phase are used to estimate the specific net nutrient consumption rate $(m)$ of the incubated community by linear regression of $\ln (C)$ and $t$ assuming

$\frac{\mathrm{d} C}{\mathrm{~d} t}=-m \cdot C$,

where $C$ is the concentration of dissolved nutrients in the sample.

\section{Results}

\subsection{Hydrographic dynamics of the nSCS}

During the survey of May 2014, waters of the nSCS can be grouped into three regions (Fig. 1): the coastal ocean zone (stations $\mathrm{C}_{1-6}$ ), the offshore pelagic zone (stations $\mathrm{C}_{7-10}$ ), and the water-intrusion zone near the Luzon Strait (stations $\mathrm{C}_{11-13}$ ). These three different zones were influenced by a diverse set of physical processes. The coastal ocean zone, which can be further separated into two subregions including the nearshore area (stations $\mathrm{C}_{1-2}$ ) and the continental shelf (stations $\mathrm{C}_{3-6}$ ), was strongly affected by wind-driven upwelling processes including Ekman transport and Ekman pumping (Gan et al., 2010). The nearshore area was characterized by low sea surface temperature (Fig. 2a) as a result of upwelling via Ekman transport driven by southwest monsoon along the shore. Ekman pumping induced by wind stress curl showed a significant increase near the edge of the continental shelf far away from the coastline (Fig. 2b). Upward transport of the deeper water with lower temperature but higher salinity along the shelf slope was clearly seen during the transect (Fig. 3a and b), which could be a result of direct upwelling or alongshore advection of upwelled waters from upstream. Both the offshore pelagic zone and the water-intrusion zone are far from the coast with bottom depths more than $2000 \mathrm{~m}$ (Fig. 1). The offshore pelagic zone was relatively stable with weak surface geostrophic currents, while the water-intrusion zone was strongly influenced by Kuroshio intrusion through the Luzon Strait (Fig. 2a).

Sea surface temperature from satellite showed a generally increasing trend from the coastal regions near Shantou to the offshore regions near Luzon Strait due to the decreasing latitude (Fig. 2a). The observed cross-shelf gradient of surface temperature from the discrete bottle measurements is in good agreement with the satellite SST data, with an average of $24.0 \pm 0.6^{\circ} \mathrm{C}$ near the coast, $25.2 \pm 0.2^{\circ} \mathrm{C}$ on the continental shelf, $28.4 \pm 0.5^{\circ} \mathrm{C}$ in the offshore pelagic zone, and $29.1 \pm 0.5^{\circ} \mathrm{C}$ near the Luzon Strait (Fig. 3a). Surface salinity was less variable than temperature from nearshore 

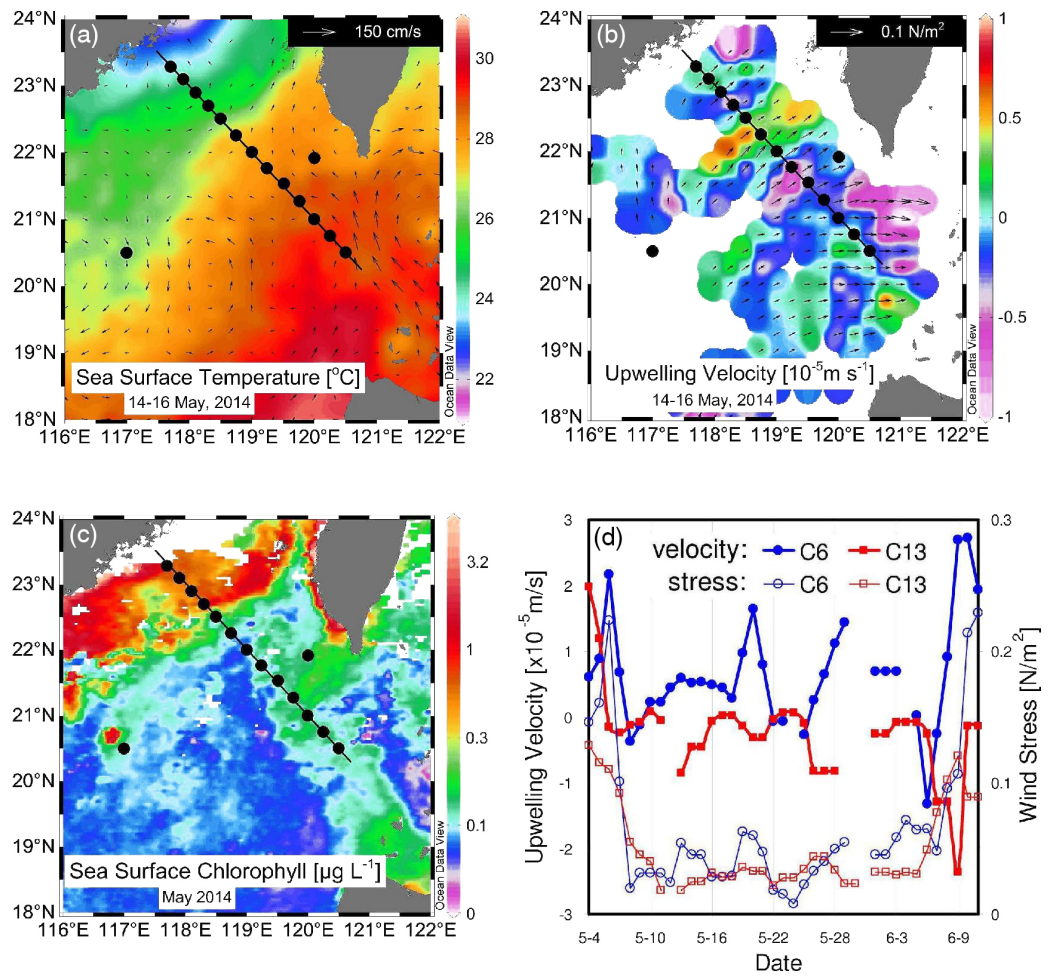

Figure 2. Spatial distributions of (a) sea surface temperature, (b) curl-driven upwelling velocity, and (c) sea surface chlorophyll during the survey, together with (d) the time-series of curl-driven upwelling and wind stress at stations $\mathrm{C}_{6}$ and $\mathrm{C}_{13}$ during the period May-June 2014 . Vectors in panels (a) and (b) are surface geostrophic currents and wind stresses, respectively; geostrophic current is from OSCAR data; upwelling velocity and wind stress are from 3-day mean METOP-ASCAT data; sea surface temperature is 3-day-mean GOES-POES data; sea surface chlorophyll $a$ is monthly MODIS-Aqua data.

to offshore with a difference of less than 0.3 during the survey (Fig. 3b). Although there was slightly higher surface salinity on the continental shelf $(34.1 \pm 0.1)$, the average salinity concentration at the surface in the coastal ocean zone $(33.9 \pm 0.2)$ was generally the same as those of the offshore pelagic zone $(33.8 \pm 0.1)$ and the water-intrusion zone $(33.9 \pm 0.3)$. Substantially higher subsurface salinities within the euphotic zone between the offshore pelagic zone and the water-intrusion zone (Fig. 3b) could come from the upwelled Pacific waters southwest of Taiwan (Chao et al., 1996).

Directions of wind stresses in the nSCS were generally southwest during the study period except for two regions where wind stress changed direction (vectors of Fig. 2b): one in the northwest of Dongsha Islands with southerly winds and the other in the Luzon Strait with westerly winds. There were several places of curl-driven upwelling in the offshore deep-water regions, though the entire area was predominantly downwelling. Large curl-driven upwelling $\left(>0.5 \times 10^{-5} \mathrm{~m} \mathrm{~s}^{-1}\right)$ was only observed near the edge of the continental shelf over abrupt changes of bathymetry. Strong temporal variations of Ekman pumping velocity (Fig. 2d) could be found in the coastal station of $\mathrm{C}_{6}$ and the offshore station of $\mathrm{C}_{13}$. Though the vertical velocities by Ekman pumping during our sampling duration of 14-16 May 2014 are relatively low, they are representative of the entire spring inter-monsoon period from 8 May to 7 June 2014 with substantially low wind intensity (Fig. 2d).

\subsection{Spatial patterns of chlorophyll $a$ and nutrients in the nSCS}

Sea surface chlorophyll $a$ in the nSCS during May 2014 was very high in the coastal ocean zone - particularly in the near-shore regions - and decreased slightly on the continental shelf (Fig. 2c). In contrast, there was generally low sea surface chlorophyll $a$ in the large areas of the offshore pelagic zone and the water-intrusion zone. Concentrations of the surface chlorophyll $a$ from discrete measurements during our survey (Fig. 3c), varying from 0.04 to $0.92 \mu \mathrm{g} \mathrm{L}^{-1}$, are in good agreement with the satellite remote sensing data. In particular, surface chlorophyll $a$ along the section shows a general seaward-decreasing trend from the costal regions of $0.72 \pm 0.36 \mu \mathrm{g} \mathrm{L}-1$ to the offshore regions of $0.09 \pm 0.04 \mu \mathrm{g} \mathrm{L}^{-1}$, which is consistent with the decrease of surface nitrate concentrations from $>1.0 \mu \mathrm{mol} \mathrm{L}^{-1}$ near the coast to $<1.0 \mu \mathrm{mol} \mathrm{L}^{-1}$ offshore (Fig. $3 \mathrm{~d}$ ). There was a surface chlorophyll patch $\left(\sim 0.3 \mu \mathrm{g} \mathrm{L}^{-1}\right)$ found at station $\mathrm{C}_{11}$ between the offshore pelagic zone and the water-intrusion 

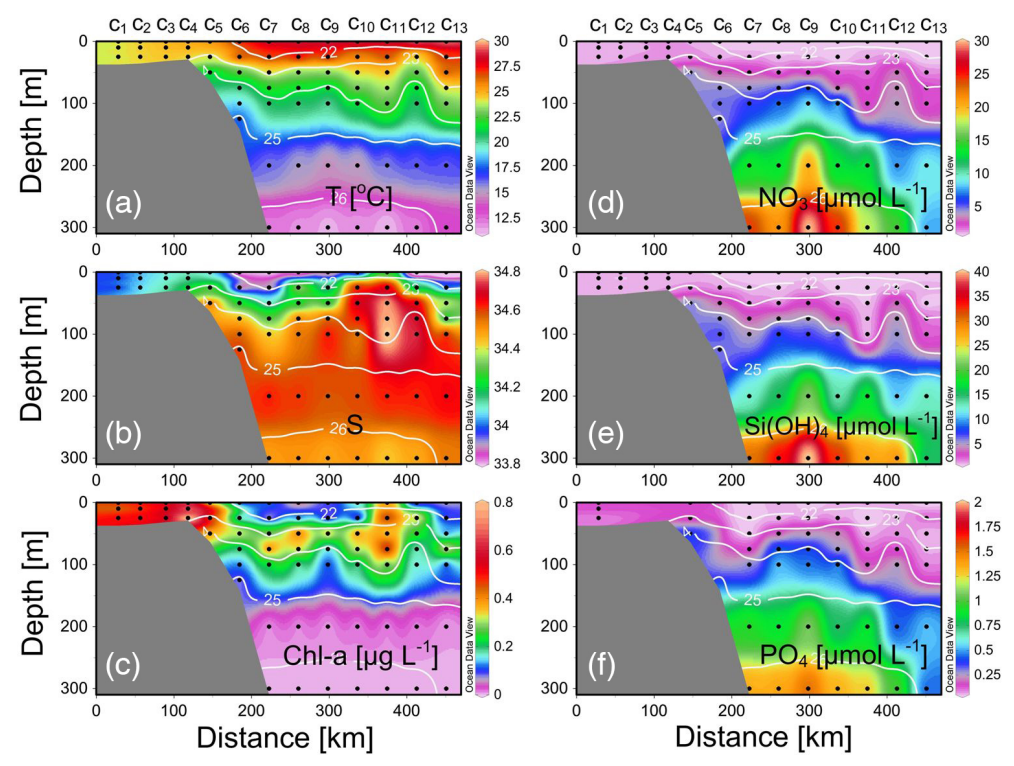

Figure 3. Vertical distributions of (a) temperature $(T)$, (b) salinity $(S)$, (c) chlorophyll $a(\mathrm{Chl} a)$, (d) nitrate $\left(\mathrm{NO}_{3}\right)$, (e) silicate $\left(\mathrm{Si}(\mathrm{OH})_{4}\right)$, and (f) phosphate $\left(\mathrm{PO}_{4}\right)$ along the coastal transect of the northern South China Sea. Overlaid white lines in each panel are isopycnals.

zone during the transect study (Fig. 3c), which could result from a surface phytoplankton bloom spreading from the southwest coast of Taiwan to the offshore regions of the central nSCS (Fig. 2c).

Phytoplankton chlorophyll $a$ was vertically well mixed in the coastal ocean zone, with clear subsurface maxima of chlorophyll $a$ only found in the offshore pelagic zone and the water-intrusion zone (Fig. 3c). The depth of the subsurface chlorophyll maxima followed the $\sigma_{\theta}=23.5$ isopycnal, which became much shallower when approaching the continental shelf from offshore. The vertical distribution of nutrients along the section generally followed the isopycnal surfaces in the upper water column (Fig. 3d-f), revealing the importance of physical control on upper ocean biogeochemistry. The observed uplifts of isopycnals as well as the depths of chlorophyll maximum and nutricline at stations $\mathrm{C}_{6}, \mathrm{C}_{8}$, $\mathrm{C}_{9}, \mathrm{C}_{10}$ and $\mathrm{C}_{12}$ are consistent with positive upwelling velocities driven by wind stress curl (Fig. 2b). Interestingly, there were substantially higher phosphate and silicate concentrations at depths of $\sim 200 \mathrm{~m}$ (across the $\sigma_{\theta}=25.5$ isopycnal) for both stations $\mathrm{C}_{9}$ and $\mathrm{C}_{11}$ in the offshore regions, which could be due to either a horizontal or vertical injection event prior to our survey. Elevated chlorophyll $a$ at station $\mathrm{C}_{11}$ was accompanied by not only the subsurface high nutrients but also the high salinity in the euphotic zone, suggesting possible vertical and horizontal nutrient transports in the upper layer. Curiously, low chlorophyll $a$ was found at station $\mathrm{C}_{9}$, which showed the highest nutrient concentrations and nutrient gradients. Along the density interval of $\sigma_{\theta}=25$ and $\sigma_{\theta}=26$ in the water-intrusion zone there was evidence for isopycnal mixing between the high-nutrient nSCS waters and the adjacent waters of Luzon Strait with lower nutrient but higher temperature/salinity.

\subsection{Vertical diffusivity and diffusive nutrient fluxes}

Turbulent diffusivity estimated by Thorpe analyses varied substantially from the edge of continental shelf to the west of Luzon Strait during May 2014 (Fig. 4). An overall averaged $K_{z}$ of $2.5 \times 10^{-4} \mathrm{~m}^{2} \mathrm{~s}^{-1}$ for the upper $300 \mathrm{~m}$ of the offshore deep-water stations is much higher than the oceanic background diffusivity of $10^{-5} \mathrm{~m}^{2} \mathrm{~s}^{-1}$, but is comparable to the previous basin-scale estimates in the nSCS (Tian et al., 2009; Liu and Lozovatsky, 2012). There were relatively high mean diffusivities of $3.6 \times 10^{-4}$ and $3.3 \times 10^{-4} \mathrm{~m}^{2} \mathrm{~s}^{-1}$ at stations $\mathrm{C}_{8}$ and $\mathrm{C}_{11}$, compared to $2.5 \times 10^{-5} \mathrm{~m}^{2} \mathrm{~s}^{-1}$ of station $\mathrm{C}_{9}$. Although the nitrate gradient at the based of euphotic zone in $\mathrm{C}_{9}\left(0.12 \mathrm{mmol} \mathrm{m}^{-2}\right)$ was about twice of that in $\mathrm{C}_{11}\left(0.06 \mathrm{mmol} \mathrm{m}^{-2}\right)$, its diffusive nitrate flux $\left(0.26 \mathrm{mmol} \mathrm{m}^{-2} \mathrm{~d}^{-1}\right)$ was only about $15 \%$ of that in $\mathrm{C}_{11}$. Our data reveal a general decreasing of mean diffusivity from $1.1 \times 10^{-3} \mathrm{~m}^{2} \mathrm{~s}^{-1}$ of $\mathrm{C}_{5}$ on the continental shelf, to $6.3 \times 10^{-4} \mathrm{~m}^{2} \mathrm{~s}^{-1}$ of $\mathrm{C}_{6}$ over the continental slope, and to $9.1 \times 10^{-5} \mathrm{~m}^{2} \mathrm{~s}^{-1}$ of $\mathrm{C}_{7}$ in the offshore pelagic zone. Yang et al. (2014) measured turbulent diffusivity along a short section near the edge of the continental shelf southwest of Taiwan using a microstructure profiler during May 2004 - about the same place as our stations $\mathrm{C}_{5}$ to $\mathrm{C}_{7}$ (Fig. 1). Their results showed high turbulent mixing over the continental shelf with a mean diffusivity of $1.6 \times 10^{-3} \mathrm{~m}^{2} \mathrm{~s}^{-1}$ but a much lower diffusivity of $5.2 \times 10^{-4} \mathrm{~m}^{2} \mathrm{~s}^{-1}$ over the slope (Yang et al., 2014), which are well comparable with our estimates using Thorpe analyses. 
Table 1. Comparisons of integrated chlorophyll $a\left(\int \mathrm{Chl} \cdot \mathrm{d} z\right)$, nitrate gradient $(\partial C / \partial z)$, nitrate concentration $\left(\mathrm{NO}_{3}\right)$, vertical diffusivity $\left(K_{z}\right)$, upwelling velocity $\left(w_{\mathrm{e}}\right)$, diffusive nitrate flux $\left(J_{\mathrm{dif}}\right)$, upwelled nitrate flux $\left(J_{\mathrm{upw}}\right)$ and total nitrate flux $\left(J_{\text {total }}\right)$ for transect stations $\mathrm{C}_{6-12}$ and incubation stations $\mathrm{A}$ and $\mathrm{B}$ at $\sim 1 \%$ light depth $(\sim 100 \mathrm{~m}$ depth $)$.

\begin{tabular}{|c|c|c|c|c|c|c|c|c|}
\hline Station & $\begin{array}{r}\int \mathrm{Chl} \cdot \mathrm{d} z \\
\left(\mathrm{mg} \mathrm{m}^{-2}\right)\end{array}$ & $\begin{array}{r}\partial C / \partial z \\
\left(\mathrm{mmol} \mathrm{m}^{-4}\right)\end{array}$ & $\begin{array}{r}\mathrm{NO}_{3} \\
\left(\mathrm{mmol} \mathrm{m}{ }^{-3}\right)\end{array}$ & $\begin{array}{r}{ }^{\mathrm{a}} K_{z} \\
\left(10^{-4} \mathrm{~m}^{2} \mathrm{~s}^{-1}\right)\end{array}$ & $\begin{array}{r}{ }^{\mathrm{b}} w_{\mathrm{e}} \\
\left(10^{-5} \mathrm{~m} \mathrm{~s}^{-1}\right)\end{array}$ & $\left(\mathrm{mmol} \mathrm{m}^{-2} \mathrm{~d}^{J_{\mathrm{dif}}}\right)$ & $\begin{array}{r}{ }^{\mathrm{c}} J_{\text {upw }} \\
\left(\mathrm{mmol} \mathrm{m}^{-2} \mathrm{~d}^{-1}\right)\end{array}$ & $\left(\mathrm{mmol} \mathrm{m}^{-2} \mathrm{~d}^{J_{\text {total }}}\right)$ \\
\hline $\mathrm{C}_{6}$ & 16.8 & 0.001 & 5.01 & $6.30 \pm 0.68$ & $0.28 \pm 0.02$ & $0.05 \pm 0.01$ & $1.21 \pm 0.09$ & $1.27 \pm 0.10$ \\
\hline $\mathrm{C}_{7}$ & 20.2 & 0.077 & 6.42 & $0.91 \pm 0.68$ & $0.03 \pm 0.05$ & $0.60 \pm 0.45$ & $0.17 \pm 0.27$ & $0.77 \pm 0.73$ \\
\hline $\mathrm{C}_{8}$ & 22.1 & 0.079 & 7.47 & $3.60 \pm 0.68$ & $-0.21 \pm 0.08$ & $2.44 \pm 0.46$ & $-1.36 \pm 0.52$ & $1.09 \pm 0.98$ \\
\hline $\mathrm{C}_{9}$ & 15.4 & 0.122 & 9.52 & $0.25 \pm 0.68$ & $-0.12 \pm 0.03$ & $0.26 \pm 0.72$ & $-0.99 \pm 0.25$ & $-0.72 \pm 0.96$ \\
\hline $\mathrm{C}_{10}$ & 21.7 & 0.082 & 9.37 & $3.45 \pm 0.68$ & $-0.18 \pm 0.03$ & $2.44 \pm 0.48$ & $-1.46 \pm 0.24$ & $0.99 \pm 0.72$ \\
\hline $\mathrm{C}_{11}$ & 38.7 & 0.060 & 2.08 & $3.30 \pm 0.68$ & $-0.27 \pm 0.07$ & $1.71 \pm 0.35$ & $-0.49 \pm 0.13$ & $1.23 \pm 0.48$ \\
\hline $\mathrm{C}_{12}$ & 20.7 & 0.029 & 3.93 & $1.53 \pm 0.68$ & $0.05 \pm 0.05$ & $0.39 \pm 0.17$ & $0.17 \pm 0.17$ & $0.56 \pm 0.34$ \\
\hline $\mathrm{C}_{13}$ & 13.2 & 0.046 & 1.98 & $2.26 \pm 0.68$ & $-0.27 \pm 0.17$ & $0.91 \pm 0.27$ & $-0.46 \pm 0.29$ & $0.44 \pm 0.56$ \\
\hline A & 15.7 & 0.047 & 2.09 & $1.60 \pm 0.68$ & $-0.09 \pm 0.04$ & $0.65 \pm 0.28$ & $-0.16 \pm 0.08$ & $0.49 \pm 0.35$ \\
\hline B & 24.8 & 0.080 & 4.82 & $4.40 \pm 0.68$ & $-0.41 \pm 0.11$ & $3.03 \pm 0.47$ & $-1.71 \pm 0.46$ & $1.33 \pm 0.93$ \\
\hline
\end{tabular}

a

${ }^{c}$ Assuming vertical velocity at the depth of $100 \mathrm{~m}$ is equal to $w_{\mathrm{e}}$.

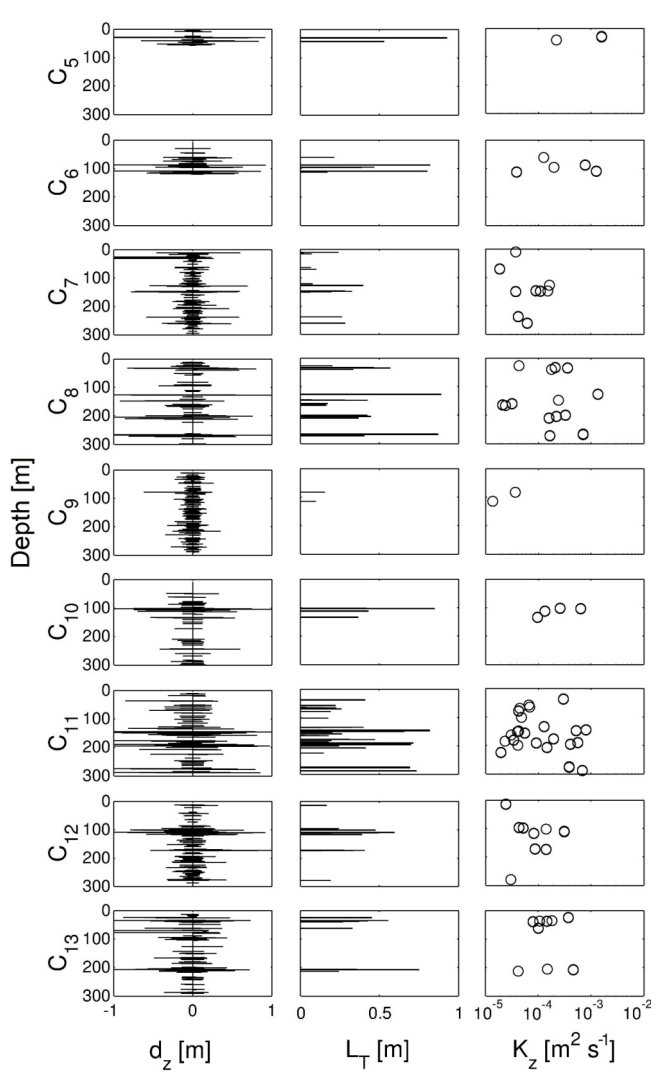

Figure 4. Profiles of Thorpe displacement $\left(d_{z}\right)$, Thorpe scale $\left(L_{\mathrm{T}}\right)$ and turbulent diffusivity $\left(K_{z}\right)$ for nine stations $\left(\mathrm{C}_{5}, \mathrm{C}_{6}, \mathrm{C}_{7}, \mathrm{C}_{8}, \mathrm{C}_{9}\right.$, $\mathrm{C}_{10}, \mathrm{C}_{11}, \mathrm{C}_{12}, \mathrm{C}_{13}$ ) from the edge of continental shelf to the west of Luzon Strait. Locations of these stations are shown in Fig. 1.

Due to intermittent nature of the turbulence dissipation, the vertical structures of diffusivity observed during our study were quite patchy (Fig. 4). In order to investigate the vertical patterns of turbulent diffusivity, we compared the observations of the two incubation stations (stations A and
B) with that of the reference time-series station $\mathrm{S}_{1}$ (Fig. 5), which had a better vertical resolution of diffusivity. It is not surprising to find that the diffusivity profile of station $\mathrm{A}$ is quite similar to that of station $\mathrm{S}_{1}$ (Fig. 5), as the two stations are very close to each other (Fig. 1). However, there are substantially higher diffusivities found in station B than in station $S_{1}$ (Fig. 5). The average diffusivity at $100 \mathrm{~m}$ during our study was about $1.6 \times 10^{-4} \mathrm{~m}^{2} \mathrm{~s}^{-1}$ in station A but about $4.4 \times 10^{-4} \mathrm{~m}^{2} \mathrm{~s}^{-1}$ in station $\mathrm{B}$. The corresponding diffusive nitrate fluxes at the base of euphotic zone were thus about $0.65 \mathrm{mmol} \mathrm{m}^{-2} \mathrm{~d}^{-1}$ in station $\mathrm{A}$ and $3.03 \mathrm{mmol} \mathrm{m}^{-2}$ $\mathrm{d}^{-1}$ in station $\mathrm{B}$, given their nitrate gradients of 0.05 and $0.08 \mathrm{mmol} \mathrm{m}^{-2}$ at $100 \mathrm{~m}$, respectively (Table 1 ). The region of the southeast Dongsha Islands near station B has been well documented for its high turbulent mixing because of internal waves (e.g., Lien et al., 2005; Chow et al., 2008). Enhanced vertical mixing by nonlinear internal waves generated at the shelf edge near Dongsha Islands (Lien et al., 2005) would lead to a higher surface chlorophyll $a$ and net primary production than the adjacent areas with less influence of internal waves during the summertime (Pan et al., 2012). The high diffusivity and diffusive nitrate flux at station B may also be contributed by physical dynamics associated with high internal waves found in this region. The frontal zones at the edge of eddies are often places of increased vertical mixing (Klein and Lapeyre, 2009; Li et al., 2012), though the eddy-induced vertical fluxes may vary substantially between cyclonic, anticyclonic and mode-water eddies (McGillicuddy et al., 2007).

\subsection{Rates of phytoplankton growth, microzooplankton grazing, and specific nutrient consumption}

The hydrographic and biogeochemical conditions of the two incubation stations were quite different, with much higher temperature (Fig. 6) and salinity (data not shown) but lower nutrients and nutrient gradients in station A than in station B (Fig. 6). Station A was at the edge of a surface phytoplank- 


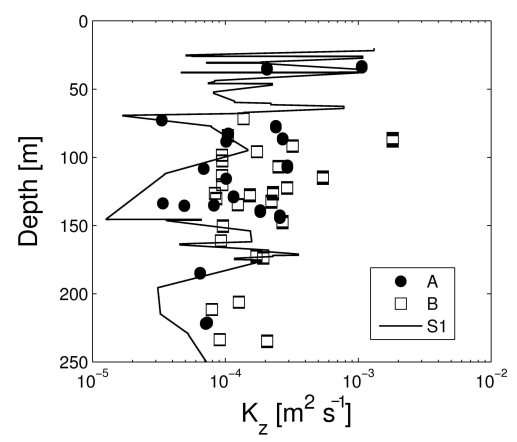

Figure 5. Comparisons of vertical turbulent diffusivities $\left(K_{z}\right)$ between two stations A and B. Black line is the result of the reference station $\mathrm{S}_{1}$ with continuous CTD sampling up to 13 casts; circles are for station A ( 2 casts) with squares for station B ( 2 casts).

ton bloom (Fig. 2c) spreading from the southwest coast of Taiwan to the offshore pelagic regions, while station B was near the central nSCS with very low sea surface chlorophyll $a$ $\left(<0.1 \mu \mathrm{g} \mathrm{L}^{-1}\right)$. Except for the surface layer, chlorophyll $a$ concentration of station $\mathrm{B}$ was generally much higher than that of station A throughout the water column. There was a clear subsurface chlorophyll maximum of $\sim 0.4 \mu \mathrm{g} \mathrm{L}^{-1}$ at $50 \mathrm{~m}$ for station B (Fig. 6), while double peaks of chlorophyll $a$ were found for station A with a surface maximum of $\sim 0.3 \mu \mathrm{g} \mathrm{L}^{-1}$ and a subsurface maximum of $\sim 0.1 \mu \mathrm{g} \mathrm{L}^{-1}$ at $75 \mathrm{~m}$.

Rates of phytoplankton growth and microzooplankton grazing at the surface were substantially different between the two stations. The nutrient-saturated phytoplankton growth rate was $1.24 \mathrm{~d}^{-1}$ at station $\mathrm{B}$, which was about three times of that at station A $\left(0.44 \mathrm{~d}^{-1}\right)$. On the other hand, the microzooplankton grazing rate of $0.43 \mathrm{~d}^{-1}$ at station A was only slightly lower than the grazing rate of $0.60 \mathrm{~d}^{-1}$ at station B (Fig. 7). The natural growth rate of phytoplankton, after correction for the effects of nutrient enrichment as described in Sect. 2.3, was $0.28 \mathrm{~d}^{-1}$ at station A, much lower than the rate of $1.18 \mathrm{~d}^{-1}$ in station $\mathrm{B}$. The rates measured at station B during May 2014 are comparable with previous estimates of growth rates of $1.03 \mathrm{~d}^{-1}$ and grazing rates of $0.62 \mathrm{~d}^{-1}$ near Dongsha Islands during July 2009 (Chen et al., 2013). Our results for station A are also in good agreement with those found in the non-upwelling area of the south Taiwan Strait (Huang et al., 2011), which suggested mean rates of $0.4-0.5$ and $0.3-0.7 \mathrm{~d}^{-1}$ for phytoplankton growth and microzooplankton grazing during July 2004 and 2005.

Incubation experiments in station A revealed an exponential growth of phytoplankton chlorophyll $a$ in response to nutrient addition within the first two days, before reaching a stable growth phase on the third day and a decay phase on the fourth day; the chlorophyll $a$ of the control experiment with raw seawater without nutrient additions quickly decreased as nutrients were consumed in the bottles (Fig. 8a). In contrast, phytoplankton of station B showed no response to nutrient
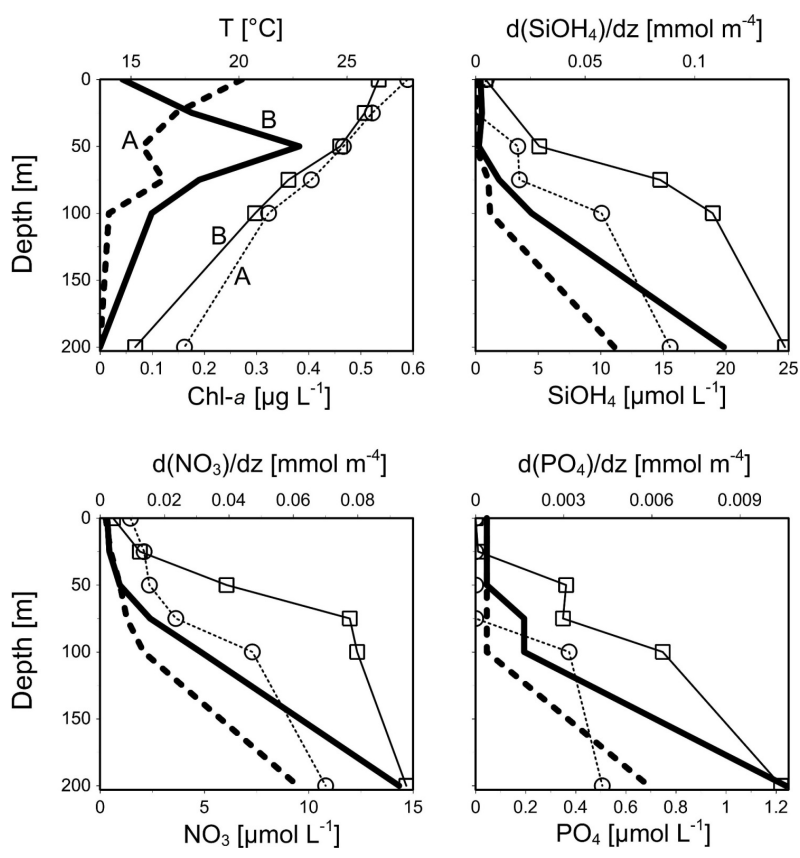

Figure 6. Comparisons of vertical profiles of chlorophyll $a(\mathrm{Chl} a)$, temperature $(T)$, nutrients $\left(\mathrm{Si}(\mathrm{OH})_{4}, \mathrm{NO}_{3}, \mathrm{PO}_{4}\right)$, and nutrient gradients between two incubation stations $\mathrm{A}$ and $\mathrm{B}$. Thick lines in each panel are for bottom axis with thin lines (open symbols) for top axis; dashed lines are for station A with solid lines for station B.

enrichment within the first two days of incubation compared to the control experiment (Fig. 8b). Significant increase of incubated chlorophyll $a$ for station B was only found during the last two days of experiment (Fig. 8b). Nutrient utilization during nutrient-enrichment incubations at these two stations were also quite different, with a much slower specific rate of nutrient consumption at station $\mathrm{B}\left(0.46 \mathrm{~d}^{-1}\right)$ than at station $\mathrm{A}$ $\left(1.03 \mathrm{~d}^{-1}\right)$. These results suggest that there was stronger nutrient limitation of the phytoplankton community at station A than station B during our cruise.

\section{Discussion}

\subsection{Roles of turbulent mixing and curl-driven upwelling on nutrient fluxes of the nSCS during the spring inter-monsoon transition period}

If the horizontal and atmospheric inputs are ignored, the total nutrient flux into the euphotic zone $\left(J_{\text {total }}\right)$ is the sum of diffusive flux due to turbulent dissipation $\left(J_{\text {dif }}=K_{z} \partial C / \partial z\right)$ and the advective flux due to upwelling $\left(J_{\text {upw }}=w C\right.$, negative for downwelling):

$J_{\text {total }}=K_{z} \frac{\partial C}{\partial z}+w C$.

To assess the roles of turbulent diffusion and Ekman pumping on vertical transport of nutrients in the nSCS, the diffu- 

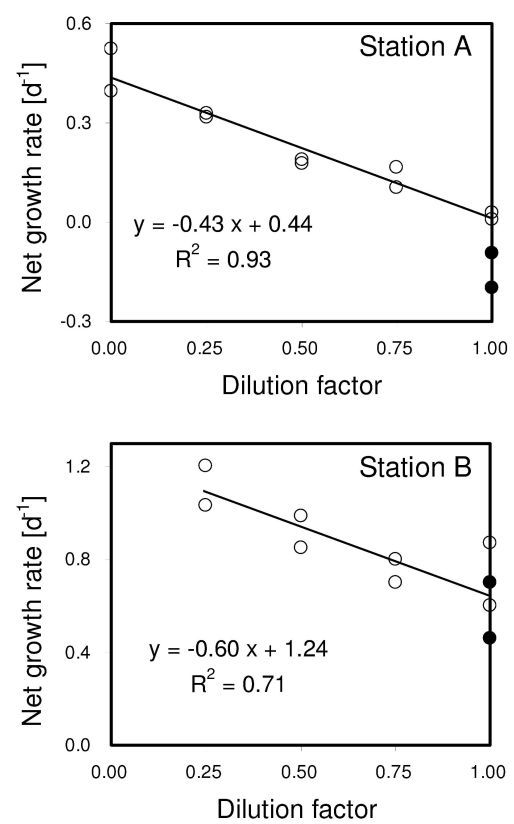

Figure 7. Dilution experiment plots of phytoplankton net growth rates against the dilution factors for stations $\mathrm{A}$ and $\mathrm{B}$. Filled circles are net growth rates of the raw seawater without nutrient enrichment.

sive and advective nitrate fluxes at the base of the euphotic zone was estimated from the continental shelf to the open sea during May 2014 (see Table 1 for details). Vertical velocity $(w)$ at the base of the euphotic zone is assumed equal to the curl-driven upwelling/downwelling velocity $\left(w_{\mathrm{e}}\right)$ by Ekman pumping. We have neglected Ekman transport as its effect is restricted only to the near coast (Gan et al., 2010). Variations of $w$ during the transect study is consistent with the isopycnal oscillation along the section (Fig. 3), suggesting the important role of Ekman pumping on physical dynamics of the water column. At the continental slope of station $\mathrm{C}_{6}$, the vertical nitrate fluxes were largely supported by curl-driven upwelling, with turbulent mixing playing a minor role due to low nitrate gradients. In contrast, the diffusive nitrate flux was over three times of the upwelled nitrate flux at station $\mathrm{C}_{7}$, immediately adjacent to $\mathrm{C}_{6}$. Except for station $\mathrm{C}_{12}$, curldriven downwelling was observed in the deep-water regions during the transect study, leading to downward transport of the low-nutrient surface water to the deeper layer. The upward nitrate fluxes in these stations were thus determined by the intensities of diffusive fluxes working against the downwelling fluxes. There was a negative nitrate flux found at station $\mathrm{C}_{9}$ where downwelling was stronger than the upward diffusion, resulting in a loss of nitrate from the euphotic zone. Our findings suggest that it is the interplay of turbulent diffusion and curl-driven upwelling/downwelling that controls the vertical fluxes of nutrients into the euphotic zone to support phytoplankton production in the nSCS.
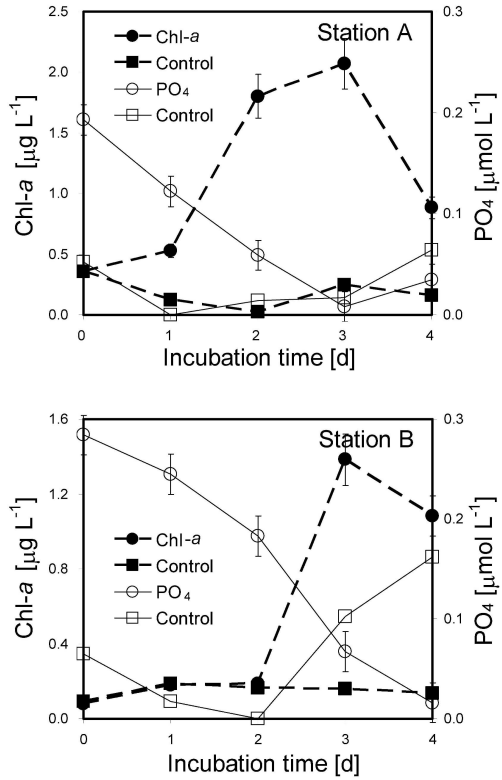

Figure 8. Temporal variations of chlorophyll $a(\mathrm{Chl} a)$ and phosphate $\left(\mathrm{PO}_{4}\right)$ during incubations with and without nutrient enrichments in stations A and B. Dashed lines (filled symbols) are for chlorophyll $a$ on the left axis with thin lines (open symbols) for phosphate on the right axis; control is the incubation of raw seawater without nutrient addition.

For the deep-water stations including the offshore pelagic zone and the water intrusion zone, the integrated chlorophyll $a$ biomass during the transect study shows a positive correlation with the upward nitrate flux $\left(\int \mathrm{Chl} \cdot \mathrm{d} z=\right.$ $\left.16.75 \times J_{\text {total }}+7.7, r^{2}=0.58, p=0.014\right)$ when station $\mathrm{C}_{9}$ is not included (Table 1), supporting the important role of bottom-up control on phytoplankton production in our study area (Chen, 2005). Station $\mathrm{C}_{6}$ should be excluded from the regression since it is near the top of the shelfslope subjecting to influence by along-shelf transport of lowchlorophyll waters, which could have resulted in the relatively lower chlorophyll $a$ biomass but higher vertical nutrient supplies observed in this station. From the regression slope of 16.75 , we could estimate a specific new production by vertical nitrate supply of $0.060 \mathrm{molN}(\mathrm{gChl})^{-1} \mathrm{~d}^{-1}$, which is slightly lower than $0.063-0.088 \mathrm{molN}(\mathrm{gChl})^{-1} \mathrm{~d}^{-1}$ reported in the nSCS by Chen (2005). Assuming a vertically constant rate of phytoplankton specific growth, a gram chlorophyll-to-carbon ratio of 0.03 and a molar $\mathrm{C} / \mathrm{N}$ ratio of 6.625 , we estimate a vertically integrated primary production of $\sim 12.3 \mathrm{mmolN} \mathrm{m}^{-2} \mathrm{~d}^{-1}$ in station $\mathrm{B}$ and $\sim 1.8 \mathrm{mmolN} \mathrm{m}^{-2} \mathrm{~d}^{-1}$ in station $\mathrm{A}$. The contribution of vertical nutrient fluxes to primary production could thus be $\sim 11$ and $\sim 26 \%$ in stations B and A, respectively, which are comparable with the $f$ ratio of $0.14-0.20$ previously estimated in the nSCS from late March to October (Chen, 2005). In steady status, the net primary production of phytoplankton should 
be balanced by the upward nutrient flux as well as the downward particle flux. Therefore, a high-nutrient flux would correspond to a high net primary production and thus a high biomass accumulation, if other conditions remain the same (species, temperature, light, grazing, etc.). Station $\mathrm{C}_{9}$ is interesting in that the vertical nutrient fluxes are net downward out of the euphotic zone, suggesting that the station may not be in steady status. High nutrients here are likely a result of strong horizontal input or a previous diapycnal nutrient injection. In this case, large drawdown of nutrients may be expected by fast-growing phytoplankton and by the downward transport of nutrients out of euphotic zone.

Uncertainty of the vertical nutrient flux could be contributed by errors in the determinations of vertical diffusivity and vertical velocity, as well as nutrient concentration and gradient. Calculation errors of vertical diffusivity by the Thorpe-scale approach, estimated from the time-series station $\mathrm{S}_{1}$, were $0.87 \times 10^{-4} \mathrm{~m}^{-2} \mathrm{~s}^{-1}$ at $50 \mathrm{~m}(n=5), 0.71 \times 10^{-4} \mathrm{~m}^{-2} \mathrm{~s}^{-1}$ at $100 \mathrm{~m}(n=6)$, and $0.46 \times 10^{-4} \mathrm{~m}^{-2} \mathrm{~s}^{-1}$ at $150 \mathrm{~m}(n=7)$. We therefore obtain an average of $0.68 \times 10^{-4} \mathrm{~m}^{-2} \mathrm{~s}^{-1}$ for the overall uncertainty of diffusivity determined in our study. Uncertainty of vertical velocity by Ekman pumping from satellite observations could be approximately determined at each station by their standard deviations over the sampling duration of 14 16 May 2014. Measurement errors of nutrients at depths during the field study should be negligible as the concentrations are considerably higher than the detection limits of the analytical methods. We are not able to quantify the uncertainty of nutrient gradient, as we have only one cast for each station with reduced resolution below the euphotic layer. Meanwhile, the nutrient gradient and related diffusive flux that we have calculated at the base of the euphotic zone could be interpreted as a mean value between the two adjacent bottle depths (100-200 m). The final uncertainties for the vertical nutrient fluxes are summarized in Table 1 , which vary substantially from 0.34 to $0.98 \mathrm{mmol} \mathrm{m}^{-2} \mathrm{~d}^{-1}(n=9)$ for stations in the offshore regions.

\subsection{Impact of growth-grazing dynamics on phytoplankton chlorophyll biomass in the nSCS}

Distributions of phytoplankton in the ocean are controlled by complex physical and biological interactions. To assess the influence of growth-grazing dynamics on phytoplankton chlorophyll $a$ biomass in the nSCS, two stations with distinct biogeochemical settings and nutrient fluxes were selected for measurements of phytoplankton growth and microzooplankton grazing rates. In addition, the community response to nutrient enrichments at the two stations was assessed by continuous incubations for up to 4 days. Previous studies indicate that surface phytoplankton community in the southeast Dongsha Islands is dominated by both diatom and picoplankton such as Prochlorococcus, while picoplankton with negligible diatoms are found in the non-upwelling area south of the Taiwan Strait during late spring and early summer (Yang, 2009; Huang et al., 2011). Our results of substantially high phytoplankton growth rates observed at station B southeast of Dongsha Islands are in agreement with its high nutrient concentrations and nutrient fluxes compared to station A south of Taiwan Strait. When released from the constraints by nutrient limitation, the phytoplankton community will be expected to shift from dominance by picoplankton toward a higher relative abundance of larger phytoplankton because of their higher intrinsic capacity for growth (Agawin et al., 2000).

The percentage of the primary production consumed by microzooplankton can be estimated by the ratio of microzooplankton grazing over phytoplankton growth $(g / \mu)$ (Landry et al., 1998). High $g / \mu$ ratios $(\sim 1.5)$ at station A suggest an elevated role of the microbial food web in the south Taiwan Strait, promoting nutrient recycling to support further phytoplankton growth, whereas the relatively higher microzooplankton grazing rate but lower $g / \mu$ ratio at station B may indicate a greater efficiency of carbon export near the Dongsha Islands, due to the greater loss of diatoms through sinking or grazing by mesozooplankton in regions with high nutrient supply (Landry et al., 1998). Natural growth of phytoplankton at station B was much higher than its grazing mortality, leading to a large net growth rate (growth minus grazing) of $0.58 \mathrm{~d}^{-1}$, which is consistent with the high integrated chlorophyll biomass in this station. In contrast, a negative net growth rate of $-0.15 \mathrm{~d}^{-1}$ was found at station A as a result of higher grazing pressure. The specific phosphate consumption rate of $1.03 \mathrm{~d}^{-1}$ at station $A$ was about twice that of station $\mathrm{B}\left(0.46 \mathrm{~d}^{-1}\right)$, suggesting a larger nutrient demand at station A. There was actually a faster response of phytoplankton to nutrient enrichment at station A than at station B, indicating a stronger nutrient limitation in the South Taiwan Strait. The negative net community growth and the higher nutrient consumption rate at station A are consistent with the spring phytoplankton bloom of the southwest of Taiwan observed in the satellite data (Fig. 2c) being in its decline phase. Indeed, the area of the phytoplankton bloom decreased substantially within 2 weeks and was not visible by the middle of June 2014 (from weekly mean sea surface chlorophyll $a$ data of MODIS Aqua) supporting the important role of grazing activity on phytoplankton distribution in the nSCS.

In conclusion, we have conducted a preliminary study on vertical nutrient fluxes and phytoplankton dynamics in the nSCS. Our results suggest that phytoplankton patchiness in the nSCS during the spring inter-monsoon of May 2014 was largely controlled by vertical nutrient fluxes, which were driven by both turbulent diffusion and wind stress curl-driven upwelling. Our results also revealed an increasing role of turbulent diffusion but a decreasing role of curl-driven upwelling in vertical transport of nutrients from the coastal ocean zones to the offshore pelagic zones in the nSCS. Elevated nutrient fluxes observed near the Dongsha Islands were found to support high new production leading to net growth 
of the phytoplankton community, whereas the low-nutrient fluxes of the South Taiwan Strait resulted in a negative net community growth leading to a decline of phytoplankton bloom. As the findings presented here are limited by the very narrow area and the very short period of sampling time, future studies may be improved by addressing the variability of vertical nutrient fluxes and its relationship to phytoplankton dynamics on a much longer timescale over a much broader area of the nSCS.

Acknowledgements. We are grateful to the captain and crew of the R/V Shiyan III for their help during the field work. We also thank two anonymous reviewers for helpful comments. This work is supported by a startup fund from a National Talent-Recruitment Program and a grant from the Chinese Academy of Sciences' Strategic Pilot Project No. XDA110202014 (to QPL).

Edited by: K. Suzuki

\section{References}

Abraham, E. R.: The generation of plankton patchiness by turbulent stirring, Nature, 391, 577-580, 1998.

Agawin, N. S. R., Duarte, C. M., and Agusti, S.: Nutrient and temperature control of the contribution of picoplankton to phytoplankton biomass and production, Limnol. Oceanogr., 45, 591600, 2000.

Bombar, D., Dippner, J. W., Doan, H. N., Ngoc, L. N., Liskow, I., Loick-Wilde, N., and Voss, M.: Sources of new nitrogen in the Vietnamese upwelling region of the South China Sea, J. Geophys. Res., 115, C06018, doi:10.1029/2008JC005154, 2010.

Centurioni, L. R., Niiler, P. P., and Lee, D. K.: Observations of inflow of Philippine Sea surface water into the South China Sea through the Luzon Strait, J. Phys. Oceanogr., 34, 113-121, 2004.

Chao, S. Y., Shaw, P. T., and Wu, S. Y.: Deep water ventilation in the South China Sea, Deep-Sea Res. Pt. I, 43, 445-466, 1996.

Chen, B., Liu, H., Landry, M. R., Dai, M., Huang, B., and Sun, J.: Close coupling between phytoplankton growth and microzooplankton grazing in the western South China Sea, Limnol. Oceanogr., 54, 1084-1097, 2009.

Chen, B., Zheng, L., Huang, B., Song, S., and Liu, H.: Seasonal and spatial comparisons of phytoplankton growth and mortality rates due to microzooplankton grazing in the northern South China Sea, Biogeosciences, 10, 2775-2785, doi:10.5194/bg-10-27752013, 2013.

Chen, Y. L.: Spatial and seasonal variations of nitrate-based new production and primary production in the South China Sea, Deep-Sea Res. Pt. II, 52, 319-340, 2005.

Chow, C., Hu, J., Centurioni, L. R., and Niiler, P. P.: Mesoscale Dongsha cyclonic eddy in the northern South China Sea by drifter and satellite observations, J. Geophys. Res., 113, C04018, doi:10.1029/2007JC004542, 2008.

Cullen, J. J., Franks, P. J. S., Karl, D. M., and Longhurst, A.: Physical influences on marine ecosystem dynamics, in: The sea, 12, edited by: Robinson, A. R., McCarthy, J. J., Rothschild, B. J., John Wiley \& Sons, New York, 297-336, 2002.
Davis, C. S., Flierl, G. R., Wiebe, P. H., and Franks, P. J. S.: Micropatchiness, turbulence and recruitment in plankton, J. Mar. Res., 43, 109-151, 1991.

Eppley, R. W. and Peterson, B. J.: Particulate organic matter flux and planktonic new production in the deep ocean, Nature, 282, 677-680, 1979.

Farris, A. and Wimbush, M.: Wind-induced intrusion into the South China Sea, J. Oceanogr., 52, 771-784, 1996.

Galbraith, P. S. and Kelley, D. E.: Identifying Overturns in CTD Profiles, J. Atmos. Ocean. Tech., 13, 688-702, 1996.

Gan, J., Lu, Z., Dai, M., Cheung, A., Liu, H., and Harrison, P.: Biological response to intensified upwelling and to a river plume in the northeastern South China Sea: A modeling study, J. Geophys. Res., 115, C09001, doi:10.1029/2009jc005569, 2010.

Gargett, A. E. and Garner, T.: Determining Thorpe scales from shiplowered CTD density profiles, J. Atmos. Ocean. Tech., 25, 16571670, 2008.

Gaube, P., Chelton, D. B., Strutton, P. G., and Behrenfeld, M. J.: Satellite observations of chlorophyll, phytoplankton biomass, and Ekman pumping in nonlinear mesoscale eddies, J. Geophys. Res., 118, 6349-6370, doi:10.1002/2013JC009027, 2013.

Gill, A. E. (Eds.): Atmosphere-Ocean Dynamics, International Geophysics Series, 30, Academic Press, London, 1982.

Han, A. Q., Dai, M. H., Gan, J. P., Kao, S.-J., Zhao, X. Z., Jan, S., Li, Q., Lin, H., Chen, C.-T. A., Wang, L., Hu, J. Y., Wang, L. F., and Gong, F.: Inter-shelf nutrient transport from the East China Sea as a major nutrient source supporting winter primary production on the northeast South China Sea shelf, Biogeosciences, 10, 81598170, doi:10.5194/bg-10-8159-2013, 2013.

Huang, B., Xiang, W., Zeng, X., Chiang, K., Tian, H., Hu, J., Lan, W., and Hong, H.: Phytoplankton growth and microzooplankton grazing in a subtropical coastal upwelling system in the Taiwan Strait, Cont. Shelf Res., 31, 48-56, 2011.

Kim, T. K., Lee, K., Duce, R., and Liss, P.: Impact of atmospheric nitrogen deposition on phytoplankton productivity in the South China Sea, Geophys. Res. Lett., 41, 3156-3162, 2013.

Klein, P., and Lapeyre, G.: The oceanic vertical pump induced by mesoscale and submesoscale turbulence, Annu. Rev. Mar. Sci., 1, 351-375, 2009.

Landry, M. R. and Hassett, R. P.: Estimating the grazing impact of marine micro-zooplankton, Mar. Biol., 67, 283-288, 1982.

Landry, M. R., Brown, S. L., Campbell, L., Constantinou, J., and Liu, B.: Spatial patterns in phytoplankton growth and microzooplankton grazing in the Arabian Sea during monsoon forcing, Deep-Sea Res. Pt. II, 45, 2353-2368, 1998.

Li, Q. P. and Hansell, D. A.: Nutrient distribution in baroclinic eddies of the oligotrophic North Atlantic and inferred impacts on biology, Deep-Sea Res. Pt. II, 55, 1291-1299, 2008.

Li, Q. P., Hansell, D. A., and Zhang, J. Z.: Underway monitoring of nanomolar nitrate plus nitrite and phosphate in oligotrophic seawater, Limnol. Oceanogr.-Meth., 6, 319-326, 2008.

Li, Q. P., Franks, P. J. S., and Landry, M. R.: Microzooplankton grazing dynamics: parameterizing grazing models with dilution experiment data in the California Current Ecosystem, Mar. Ecol. Prog. Ser., 438, 59-69, 2011.

Li, Q. P., Franks, P. J. S., Ohman, M. D., and Landry, M. R.: Enhanced nitrate flux and biological processes in a frontal zone of the California Current System, J. Plankton Res., 34, 790-801, 2012. 
Li, Q. P., Wang, Y., Dong, Y., and Gan, J.: Modeling long-term change of planktonic ecosystems in the Northern South China Sea and the upstream Kuroshio Current, J. Geophys. Res., 120, 3913-3936, doi:10.1002/2014JC010609, 2015.

Lien, R., Tang, T., Chang, M., and D'Asaro, E. A.: Energy of nonlinear internal waves in the South China Sea, Geophys. Res. Lett., 32, L05615, doi:10.1029/2004GL022012, 2005.

Lin, I., Wong, G. T. F., Lien, C., Chien, C., Huang, C., and Chen, J.: Aerosol impact on the South China Sea biogeochemistry: an early assessment from remote sensing, Geophys. Res. Lett., 36, L17605, doi:10.1029/2009GL037484, 2009.

Lin, I., Lien, C., Wu, C., Wong, G. T. F., Huang, C., and Chiang, T.: Enhanced primary production in the oligotrophic South China Sea by eddy injection in spring, Geophys. Res. Lett., 37, L16602, doi:10.1029/2010GL043872, 2010.

Liu, K. K., Chao, S. Y., Shaw, P. T., Gong, G. C., Chen, C. C., and Tang, T. Y.: Monsoon-forced chlorophyll distribution and primary production in the South China Sea: observations and a numerical study, Deep-Sea Res. Pt. I, 49, 1387-1412, 2002.

Liu, Z. Y. and Lozovatsky, I.: Upper pycnocline turbulence in the northern South China Sea, Chinese Sci. Bull., 57, 2302-2306, 2012.

McGillicuddy, D. J., Anderson, L., Bates, N., Bibby, T., Buesseler, K., Carlson, C., Davis, C., Ewart, C., Falkowski, P., Goldthwait, S., Hansell, D. A., Jenkins, W. J., Johnson, R., Kosnyrev, V., Ledwell, J. R., Li, Q. P., Siegel, D. A., and Steinberg, D. K.: Eddy-wind interactions stimulate extraordinary mid-ocean plankton blooms, Science, 316, 1021-1026, 2007.

Osborn, T. R.: Estimates of the local rate of vertical diffusion from dissipation measurements, J. Phys. Oceanogr., 10, 83-89, 1980.

Pan, X., Wong, G. T. F., Shiah, F. K., and Ho, T. Y.: Enhancement of biological production by internal waves: observations in the summertime in the northern South China Sea, J. Oceanogr., 68, 427-437, 2012.
Parsons, T. R., Maita, Y., and Lalli, C. M. (Eds.): A manual of chemical and biological methods for seawater analysis, Pergamum Press, Oxford, 1984.

Risien, C. M. and Chelton, D. B.: A global climatology of surface wind and wind stress fields from eight year QuickSCAT scatterometer data, J. Phys. Oceanogr., 38, 2379-2412, 2008.

Rykaczewski, R. R. and Checkley, D. M.: Influence of ocean winds on the pelagic ecosystem in upwelling regions, P. Natl. Acad. Sci., 105, 1065-1970, 2008.

Tian, J., Yang, Q., and Zhao, W.: Enhanced diapycnal mixing in the South China Sea, J. Phys. Oceanogr., 39, 3191-3203, 2009.

Thorpe, S. A.: Turbulence and mixing in a Scottish loch, Philos. T. R. Soc. A, 286, 125-181, 1977.

Wang, J. and Tang, D.: Phytoplankton patchiness during spring intermonsoon in west coast of South China Sea, Deep-Sea Res. Pt. II, 101, 120-128, 2014.

Yang, Q., Tian, J., Zhao, W., Liang, X., and Zhou, L.: Observations of turbulence on the shelf and slope of northern South China Sea, Deep-Sea Res. Pt. I, 87, 43-52, 2014.

Yang, Y. H.: Phytoplankton community structure of the northern South China Sea and the Philippine Sea, Master Thesis (in CHN), National Taiwan Normal University, Taiwan, 73 pp., 2009.

Zhou, L., Tan, Y., Huang, L., Huang, J., Liu, H., and Lian, X.: Phytoplankton growth and microzooplankton grazing in the continental shelf area of northeastern South China Sea after typhoon Fengshen, Cont. Shelf Res., 31, 1663-1671, 2011. 